\title{
Cover essay
}

\author{
Mark Antliff
}

Published online: 29 May 2009

(C) Springer Science + Business Media, LLC 2009

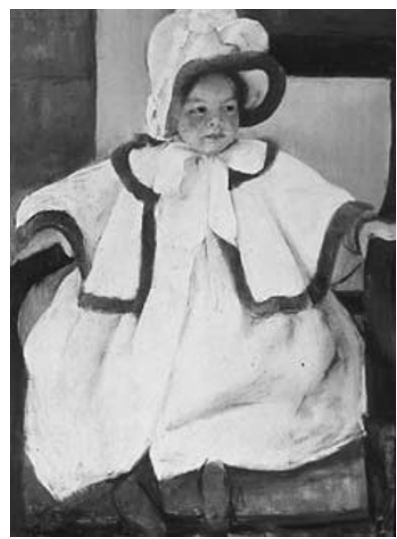

Mary Cassatt, Ellen Mary Cassatt in a White Coat, c. 1896.

Boston Museum of Fine Arts.

Like her friend and fellow artist Berthe Morisot, the American born Mary Cassatt (1844-1926) was a prominent member of the Impressionist movement who shared Morisot's interest in the psychological impact of societal mores on women and young children. Beginning in 1878 Cassatt painted a series of images of lone children in public settings which culminated in this portrait of Ellen Mary Cassatt. Seated precariously on an eighteenth-century armchair, Ellen Mary is depicted from what art historian Griselda Pollock has termed a phenomeno-

logical perspective so that we as viewers are implicitly called upon to empathize with this youthful sitter. Rather than observing the child from above or at a distance, the imagined beholder is instead positioned as if crouching and in close proximity. Ellen Mary's fur lined white coat and bonnet make clear the bourgeois social status of her parents, but the clothes also act as a metaphor for the binding rules of decorum that are already shaping the child's behavior in public. The contrast in scale between her tiny body and the adult sized chair is further emphasized by her uncertain grasp of the arm rests and the tiny feet which barely reach the edge of the chair's seat. The little girl looks joyless as she gazes from beneath her oversized bonnet at some unseen interlocutor. Her diminutive bodily features are thus overwhelmed by her sumptuous clothing, which portends a future governed by the societal codes of the upper bourgeoisie. These elements, when combined with the claustrophobic positioning of the chair in a corner, underline the curtailment of the infant's freedom to act her age and allude to the social forces that will shape her life as an adult.

M. Antliff $(\triangle)$

Art History \& Visual Studies, Duke University,

115 East Duke Bldg, Box 90764, Durham, NC 27708, USA

e-mail: antliff@duke.edu 